qul

JAN 131965

Standard Reference Materials:

\title{
METALLOGRAPHIC CHARACTERIZATION OF AN NBS SPECTROMETRIC LOW-ALLOY STEEL STANDARD
}

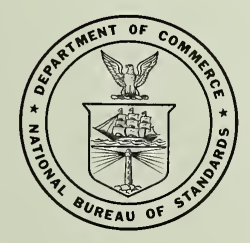

U.S. Department of Commerce

National Bureau of Standards 


\section{THE NATIONAL BUREAU OF STANDARDS}

The National Bureau of Standards is a principal focal point in the Federal Government for assuring maximum application of the physical and engineering sciences to the advancement of technology in industry and commerce. Its responsibilities include development and maintenance of the national standards of measurement, and the provisions of means for making measurements consistent with those standards; determination of physical constants and properties of materials; development of methods for testing materials, mechanisms, and structures, and making such tests as may be necessary, particularly for government agencies; cooperation in the establishment of standard practices for incorporation in codes and specifications; advisory service to government agencies on scientific and technical problems; invention and development of devices to serve special needs of the Government; assistance to industry, business, and consumers in the development and acceptance of commercial standards and simplified trade practice recommendations; administration of programs in cooperation with United States business groups and standards organizations for the development of international standards of practice; and maintenance of a clearinghouse for the collection and dissemination of scientific, technical, and engineering information. The scope of the Bureau's activities is suggested in the following listing of its four Institutes and their organizational units.

Institute for Basic Standards. Electricity. Metrology. Heat. Radiation Physics. Mechanics. Applied Mathematics. Atomic Physics. Physical Chemistry. Laboratory Astrophysics. ${ }^{*}$ Radio Standards Laboratory: Radio Standards Physics; Radio Standards Engineering. ${ }^{* *}$ Office of Standard Reference Data.

Institute for Materials Research. Analytical Chemistry. Polymers. Metallurgy. Inorganic Materials. Reactor Radiations. Cryogenics. ${ }^{* *}$ Office of Standard Reference Materials.

Central Radio Propagation Laboratory.** Ionosphere Research and Propagation. Troposphere and Space Telecommunications. Radio Systems. Upper Atmosphere and Space Physics.

Institute for Applied Technology. Textiles and Apparel Technology Center. Building Research. Industrial Equipment. Information Technology. Performance Test Development. Instrumentation. Transport Systems. Office of Technical Services. Office of Weights and Measures. Office of Engineering Standards. Office of Industrial Services.

* NBS Group, Joint Institute for Laboratory Astrophysics at the University of Colorado.

* * Located at Boulder, Colorado. 
UNITED STATES DEPARTMENT OF COMMERCE - Luther H. Hodges, Secretary NATIONAL BUREAU OF STANDARDS • A. V. Astin, Director

\title{
Standard Reference Materials:
}

\section{Metallographic Characterization of an NBS Spectrometric Low-Alloy Steel Standard}

\author{
R. E. Michaelis, H. Yakowitz, and G. A. Moore \\ Institute for Materials Research \\ National Bureau of Standards \\ Washington, D.C.
}
Reprinted from the Journal of Research of the National
Bureau of Standards-A. Physics and Chemistry

Vol. 68A No. 4, July-August 1964, with an appendix added

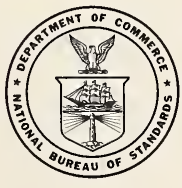

National Bureau of Standards Miscellaneous Publication 260-3

Issued October 22, 1964 


\section{Library of Congress Catalog Card Number : 64-60094}




\section{PREFACE}

Within the framework of the NBS Institute for Materials Research the area of standard reference materials is a broad and important one, including the preparation, characterization and distribution of a wide variety of materials in such diverse fields as metallurgy, polymers and inorganic materials. In carrying out such a program there is much interaction with representatives of industry and science, beginning with discussions as to which primary standard materials will do most to advance technology, the furnishing of materials and fabrication of samples, and the characterization and certification of the materials by cooperative efforts. The many groups participating in a standards program are very interested in detailed information on specific aspects of the program -but to date there has been no publication outlet for such written discussions.

To meet this need, NBS Miscellaneous Publication 260 has been reserved for a series of papers in the general area of "standard reference materials". This series will present the results of studies and investigations undertaken within the Institute for Materials Research with emphasis on the preparation and characterization of standard reference materials. This subject-oriented series will provide a means for rapid dissemination of this detailed information and we hope will stimulate the use of standard reference materials in science and industry. 


\section{OTHER NBS PUBLICATIONS OF INTEREST}

NBS Miscellaneous Publication 260-1, Preparation of NBS White Cast Iron Spectrochemical Standards, June 1964. 30 cents.

NBS Miscellaneous Publication 260-2, Preparation of NBS CopperBase Spectrochemical Standards, October 1964. 35 cents.

NBS Miscellaneous Publication 241, Standard Materials Issued by the National Bureau of Standards: A Descriptive List with Prices, March 1962. 30 cents. Up-to-date supplementary insert sheets to Misc. Publ. 241 list new, renewal, out of stock, and discontinued standards. This sheet is available without charge directly from the National Bureau of Standards, Washington, D.C., 20234.

NBS Miscellaneous Publication 250, Calibration and Test Services of the National Bureau of Standards, November 1963. 70 cents.

Send orders with remittance to: Superintendent of Documents, U. S. Government Printing Office, Washington, D.C., 20402. Remittances from foreign countries should include an additional one-fourth of the purchase price for postage. 
1. INTRODUCTION . . . . . . . . . . . . . . 1

2. SELECTION OF MATERIAL FOR STUDY . . . . . . . . 1

3. INFORMATION DESIRED AND EQUIPMENT USED . . . . . 2

4. EXPERIMENTAI PROCEDURE . . . . . . . . . 2

4.1. Electron Probe Microanalysis . . . . . 2

4.2. Computer Metallography .. . . . . 3

4.3. Inclusion Counting . . . . . . . . 4

4.4. Studies on Etched Structures . . . . . 6

5. RESULTS . . . . . . . . . . . . 6

5.1. Homogeneity . . . . . . . . . 6

a. Nickel in the Cross Section. . . . 6

b. Iron in the Cross Section ... . . 6

c. Nickel in the Longitudinal Section 6

d. Iron in the Longitudinal Section . 7

5.2. Inclusions in the steel . . . . . . 8

a. Identification of the Inclusions . 8

b. Volume and Weight Percentages of Nonmetallic Inclusions . . . . 8

c. Estimation of the Weight Percent of Inclusions . . . . . . . . 8

d. Estimation of Number and Size of Inclusions . . . . . . . . . 8

e. Mean Free Path Between Inclusions 9

5.3. Analysis of the Etched Structure in NBS-461 steel .. . . . . . . . 9

a. Ferrite and Pearlite Percentages . 9 


\section{CONTENTS - Continued}

b. Mean Free Paths for Ferrite and

Pearlite . . . . . . . . 10

c. Grain Size of the Steel ..... 10

6. DISCUSSION . . . . . . . . . . . . 11

7. SUMMARY OF RESULTS ON NBS-46I STEEL . . . . . . II

7.1. Homogeneity . . . . . . . . . 11

7.2. Inclusions . . . . . . . . . . . 12

7.3. Characteristics of the Steel . . . . 12

8. REFERENCES . . . . . . . . . . . 12

APPENDIX . . . . . . . . . . . . . 13

LIST OF TABLES

TABLE NO.

PAGE

1. NBS Spectrographic low-alloy steel standard No. 461 . . . . . . . . . . 2 2

2. Nickel concentration in cross sections of NBS-461 steel

3. Nickel concentration in longitudinal sections of NBS-461 steel . . . . . . . . . .

\section{LIST OF FIGURES}

FIGURE No.

PAGE

1. NBS-46I steel polished for inclusion counting and microprobe examination

2. Typical inclusion in longitudinal section . . . 5

3. Cross section of NBS-46I steel etched for $9 \mathrm{~s}$ in 3-1/2 percent $\mathrm{HNO}_{3}$

4. Longitudinal section of NBS steel etched for $10 \mathrm{~s}$ in $3-1 / 2$ percent $\mathrm{HNO}_{3}$

5. Histogram of ASTM grain size numbers in NBS-461 steel 


\title{
Metallographic Characterization of an NBS Spectrometric Low-Alloy Steel Standard
}

\author{
R. E. Michaelis, H. Yakowitz, and G. A. Moore
}

(January 2, 1964)

\begin{abstract}
The spectrometric standard steel designated NBS Low-Alloy Steel 461 was investigated by means of electron probe microanalysis and quantitative metallographic techniques employing a digital computer. Electron probe microanalysis showed the steel to be homogeneous in nickel and iron at two to four microns of spatial resolution. The average of all determinations agreed with the certified values for these elements. Inclusions in the steel were identified, classified as to size and shape, and counted. Mean free path data on the inclusions were calculated. The ASTM ferrite grain size number was deduced as 13.5 for the steel in the unetched condition. From the mean free paths in ferrite and pearlite, it was found that the steel is structurally homogeneous at a five micron level. It is concluded that the homogeneity level corresponds closely to the grain size of the material. It is further concluded that NBS-461 steel is sufficiently homogeneous that any present microanalytical technique can be carried out with little chance of inaccuracy due to inhomogeneity.
\end{abstract}

\section{Introduction}

Most of the modern rapid instrumental methods of analysis depend on the use of standard samples of composition for calibration. The National Bureau of Standards in cooperation with industrial and government groups, plans, prepares, tests, and certifies selected standards of composition to serve the urgent needs of science and technology in critical areas of calibration.

Whereas generally suitable techniques have been developed for the preparation of homogeneous standard samples of composition to be applied in chemical analysis, or in the usual optical emission and $\mathrm{x}$-ray spectrochemical analysis, $[1]^{1}$ some of the newer analytical methods are far more demanding with respect to the requirement of homogeneity. Included in the newer analytical techniques which have stringent requirements for sample homogeneity at the 1 to $50 \mu$ level are those involving the solids mass spectrometer, the laser excitation source in spectrochemical analysis, and the electron-probe microanalyzer. The latter instrument, for example, can perform an analysis with a spot diameter of about $1 \mu$.

An important objective of the spectrochemical standards program is to develop new or improved procedures and methods for preparing, testing, analyzing, and applying the spectrochemical standards. In this, research is directed not only to techniques for providing standards with high measurement excellence, but also to procedures for increasing the applicability of existing and future standards.

The purpose of this report is to present the results of a limited but critical evaluation of homogeneity at the 2 to $4 \mu$ level in one of the available NBS

\footnotetext{
1 Figures in hrackets indicate the literature references at the end of this paper.
}

steel spectrochemical standards. The evaluation is intended (1) to provide a more complete characterization of the standard, and (2) to learn of its suitability for application to the newer analytical techniques. The investigation primarily involves a study by the NBS electron probe microanalyzer and by new quantitative metallographic techniques.

\section{Selection of Material for Study}

At present, the NBS does not have available specific standard samples of composition for some of the newer analytical techniques, such as the solids mass spectrometer. However, a number of available NBS standard samples, designed primarily for application in spectrochemical analysis, was prepared and processed to yield material of high homogeneity. Based on the results of extensive testing several years ago by optical emission and $x$-ray spectrochemical analysis, by chemical analysis, and by metallographic studies, these standard samples were determined to be free from segregation, for the intended applications, for most contained elements. In particular, a set of eight ingot iron and low-alloy steel standards, prepared in the years 1956 and 1957 to contain a graded composition range for about 25 elements, was found to be homogeneous at a level of about $1 \mathrm{~mm}$ $(1000 \mu)$ for most elements as based on the methods of test then available. It was believed that one of these standards would serve the purpose of this investigation.

The study of photomicrographs of these irons and steels indicated structural inhomogeneity for all eight standards at the micron level; however, at least two of the standards appeared to exhibit suitable structural homogeneity at the 10 to $20 \mu$ level. The latter level should be satisfactory for application to either the solids mass spectrometer or to the laser excitation source in optical emission analysis. 
The material for each standard had been melted in a one-ton induction furnace (high frequency) at the Naval Research Laboratory and cast into a single ingot. In an effort to reduce the number of inclusions, and to improve and standardize the recovery values for the additions, each heat was given a "carbon boil" immediately after melt down. Also, as a possible aid to reducing the inclusions in the final material and to obtaining a finer grain size, a rare earth addition was made to the molten metal in the ladle prior to skimming and pouring into the mold.

Each ingot was processed by forging to a slab having one dimension of the cross section four times that of the other dimension. After cropping top and bottom, 15 and 5 percent respectively, the slab was cut lengthwise and the central longitudinal section corresponding to one-fourth of the slab was discarded. The remaining two slab portions were hot rolled to oversize rods, annealed, straightened, and centerless ground to size. About $900 \mathrm{lb}$ (408.6 $\mathrm{kg}$ ) of finished rods were obtained for each standard as follows: $100 \mathrm{lb}(45.4 \mathrm{~kg})$ of rods $7 / 32 \mathrm{in} .(5.56 \mathrm{~mm})$ in diameter from the outer section near the bottom of the original ingot; $400 \mathrm{lb}(181.6 \mathrm{~kg})$ of rods $1 \frac{114}{4}$ in. $(31.75 \mathrm{~mm})$ in diameter from the outer sections near the middle of the original ingot that is currently certified; and additionally, $400 \mathrm{lb}$ of rods $11 / 4 \mathrm{in}$. in diameter which will be issued as renewal material when the first $400-1 b$ lots are exhausted.

As would be expected, the rod material $7 / 32$ in. in diameter received far more severe working than the larger size of $1 \frac{11}{4}$ in. in diameter, hence, the smaller rods exhibited a much finer grain size.

The decision was made to confine the initial investigation by the electron probe microanalyzer and by the new quantitative metallographic techniques to NBS Spectrochemical Standard No. 461. The composition of this steel is shown in table 1 .

A random sample was chosen as typical of the entire $100 \mathrm{lb}$ lot. Previous metallographic examination of several selected samples revealed no significant differences.

TABLE 1. NBS Spectrographic low-alloy steel standard No. 461

Provisional certified analysis (November 25, 1959)

\begin{tabular}{|c|c|c|c|}
\hline Element & Wt & Element & Wt \\
\hline $\begin{array}{l}\mathrm{Fe} \\
\mathrm{C} \\
\mathrm{M} n \\
\mathrm{P} \\
\mathrm{S} \\
\mathrm{Si} \\
\mathrm{Cu} \\
\mathrm{Ni} \\
\mathrm{Cr} \\
\mathrm{V} \\
\mathrm{M} \mathrm{N}_{2} \\
\mathrm{Sn} \\
\mathrm{Ti}\end{array}$ & $\begin{array}{c}\% \\
*(96.47) \\
0.15 \\
.36 \\
.053 \\
(.02) \\
.047 \\
.34 \\
1.73 \\
0.13 \\
.024 \\
.30 \\
.022 \\
(.01)\end{array}$ & 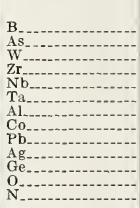 & $\begin{array}{l}\% \\
0.000_{2} \\
.028 \\
.012 \\
(<.005) \\
.011 \\
.002 \\
(.005) \\
.26 \\
(.003) \\
\left(.001_{5}\right) \\
\left(.001_{5}\right) \\
\left(.02_{0}\right) \\
\left(.00_{6}\right)\end{array}$ \\
\hline
\end{tabular}

*Values in parenthesis are not certified, but are given for information on the composition. Iron percent is by difference.

\section{Information Desired and Equipment Used}

It was desired to determine whether the steel was homogeneous in nickel and iron at micron levels of spatial resolution in the longitudinal, transverse, and normal directions. Furthermore, the average of a set of analyses for these two elements was to be checked against the certified value. For this purpose, the NBS electron probe microanalyzer was employed. This instrument, which enabled analyses to be made at the 2 to $4 \mu$ level, has been described in detail elsewhere [2].

Since inclusions were found in the steel, they had to be identified; here both the electron probe microanalyzer and chemical-etching techniques were employed. Additional desirable information concerning the inclusions consisted of their volume percentage in the steel, the mean free path between them, and some idea of their number and size distribution.

Concerning the steel itself, the following information was required: (a) a statement of the apparent ferrite and pearlite percentages in the worked structure of the steel, (b) the mean free path for ferrite and pearlite, and finally (c) the grain size of the steel.

It is apparent that in order to obtain the required information, beyond the mere identification of the inclusions, one must resort to accurate quantitative metallography.

\section{Experimental Procedure}

\subsection{Electron Probe Microanalysis}

To check the chemical homogeneity of the steel, both nickel and iron were investigated for uniformity of composition throughout the sample of 461 . With the NBS electron probe microanalyzer, 46 separate spot determinations were made for nickel in the cross section and 62 determinations were made in the longitudinal section For iron, the corresponding determinations were 9 and 16 , respectively. This gives a total of 108 separate nickel determinations and 25 separate iron determinations.

The electron probe microanalyzer was operated at $32.5 \mathrm{keV}$ for all analyses. Specimen currents used were $3.5 \times 10^{-8}( \pm 1 \%) \mathrm{A}$ for the cross section and $1.0 \times 10^{-7}( \pm 1 \%) \mathrm{A}$ for the longitudinal section. Observed line to background ratios were 20/1 for pure iron and $30 / 1$ for pure nickel using the second order unresolved $K \alpha$ doublet for these elements in conjunction with an ADP crystal $^{2}$ and a flow proportional counter. Using the first order unresolved $K \alpha$ doublet for nickel in conjunction with a $\mathrm{LiF}$ crystal and a G-M counter, the observed line to background ratio was $210 / 1$ for pure Ni. The probe size was 2 to $4 \mu$ based on examination of the contamination spots formed.

${ }^{2}$ ADP refers to an ammonium dihydrogen phosphate crystal, which bas a $2 \mathrm{~d}$ spacing of $10.65 \AA$. 
The $x$-ray intensities from the sample were compared to those obtained for pure metal endmember standards. The corrections applied were as follows:

Absorption: Philibert [3].

Fluorescence: Birks [4] (enhancement of Fe-Ko by $1.73 \% \mathrm{Ni}$ ).

Atomic Number [5]: Not required.

Effect of continuous radiation [6]: Neglected.

An appendix showing the detailed calculations for this paper is available on request [7].

\subsection{Computer Metallography}

A process which makes accurate quantitative metallography economically practical is one which employs a digital computer capable of accepting suitable photomicrographs and of printing out the desired information directly [8]. The computer which has been used to date is the SEAC (Standards Electronic Automatic Computer). Black and white pictures may be directly introduced in binary machine code by a scanning device. This equipment places a physical size limitation on the photomicrograph to be investigated since the scanning device can accommodate only one picture, $44 \mathrm{~mm}^{2}$, at a time.

At present, 28 general operations may be performed on a suitable micrograph. Many of these have been described previously [9]. New operations used in this study are known as "SLICE," "BLOB TRANSFER," "BLOB CUSTER," and "STATISTICS" respectively and these will be described herein.

The photomicrographs to be scanned must have the highest possible contrast bctween black and white areas because the accuracy of the machine is adversely affected by gray components. The size and shape of the areas to be shown as black must be truly representative of the sample at the magnification chosen. Furthermore, all grain boundaries revealed by etching must be shown as completed networks since the computer will find any openings and count such paired grains as single grains.

The computer scans a raster of square spots $0.25 \mathrm{~mm}$ on an edge. For example, if the photomicrograph is taken at a magnification of 500 diam, the computer unit will be $0.25 / 500$ or $5 \times 10^{-4} \mathrm{~mm}$ which corresponds to $0.50 \mu$. Therefore, the magnifications used must be known accurately if data such as mean free paths are to be meaningful.

To obtain the metallographic information desired, the machine was required to state the area of the black phase, to display the picture on an oscilloscope screen, to "slice" the picture horizontally and vertically, and to perform lineal analyses at right angles to each other. In certain cases, complete "blob" (any discrete black area) analyses were ordered from which complete data on each blob in the picture were deduced and printed out.

To accomplish all of these orders, a master routine is fed into a portion of the computer memory. This will cause the computer to demand a list of orders which are in the form of English words. Given this list, the computer stores the commands and carries them out in the listed sequence. To perform a command, the computer searches the order tape until it locates the matching title. It then reads in the detailed orders and executes this set of orders. The operator, in effect, causes the machine to execute literally thousands of orders in machine language by simply typing in a list of commands in English. To do the complete series of analyses required for obtaining all the information desired about one micrograph of the NBS-461 steel, the simplified English language command list to the computer is:

SCAN. This causes the computer to be supplied with one picture $44 \mathrm{~mm}^{2}$. A blank border $1 \mathrm{~mm}$ wide is masked onto the picture. The net usable area within the border is 28,224 bits.

AREA. This counts the number of black bits in the image. Division by 28,224 gives the percentage of the phase represented by the image. The area statement is checked by using a calibrated bar chart containing 14,112 black bits which is exactly half the usable picture area of 28,224 bits (704 SEAC words).

DISPLAY. The image which is stored in the computer memory is exhibited on a cathode ray tube.

DUMP. The image in the machine is electrically recorded on wire or tape.

SLICE HORIZONTALLY or SLICE VERTICALLY. The slice operation separately determines the areas of 168 horizontal or vertical line slices. The decimal print out classifies the 168 slices into a histogram of 27 classes. The upper limit of each class and the number of slices found therein is stated.

The area is given in bits and in percent of the net image area $(28,224$ bits $)$. A $\sigma$ value, based on the histogram of the line slice distribution, is given in percent and the $\sigma$ value of the mean area is given in bits and in percent. The $\sigma$ values may be expected to differ for horizontal and vertical slicings. The larger of the two $\sigma$ values is used.

LINE. This causes the computer to treat the picture as an unbroken horizontal helical raster such as would result from wrapping the picture around a vertical cylinder and joining the right end of each scan line to the left end of the next line. This order produces a decimal table presenting a histogram (on $\sqrt{2}$ classes) of line lengths in the black and white portions of the picture. The mean free path is computed as well as the standard deviations of both path length distributions and of the mean free path.

ROTATE. The picture is turned $90 \mathrm{deg}$ as may be required for a directional interpretation.

LINE. This second LINE order gives the lineal analysis at right angles to the first LINE order.

BLOB TRANSFER AND RECORD. Each black blob in the picture is analyzed separately. The computer prints out the serial number, area, addresses of the corners of the circumscribed rectangle, height, width, estimated length $(L)$, estimated thickness $(T)$, and the shape factor $(L / T)$. 
BLOB CUSTER. This operation reads back the data from the BLOB TRANSFER AND RECORD table together with an image of the single blob and computes the perimeter $(P)$ of each blob as well as the complexity factor, $P^{2} /$ area. The table so constructed contains the input data for the statistical analysis.

STATISTICS. The data from the BLOB CUSTER table are classified into histogram tables of eleven blob parameters on logarithmetically increasing classes of base $\sqrt{2}$. Automatic corrections for blobs cut by the picture edges are made.

END. Machine stops.

\subsection{Inclusion Counting}

The longitudinal and cross sections were polished for inclusion counting, i.e., to reveal the true number, size, and distribution of the inclusions. This was accomplished by performing the final polishing with a quarter-micron diamond powder on micro-cloth for long times at low speeds. The sample was alternately etched and polished and was finished in the unetched condition.

The criteria adopted for the inclusion polishing were as follows: (1) that there be no scratches in the area to be photographed when this area was subjected to rotation in polarized light, (2) that "open circles" were not true inclusions, (3) that the inclusions have sharp boundaries at the magnification of interest. When these criteria were satisfied, it was believed that a true representation of the inclusion concentration had been obtained. After being photographed in this condition, the samples were introduced into the NBS electron probe microanalyzer.

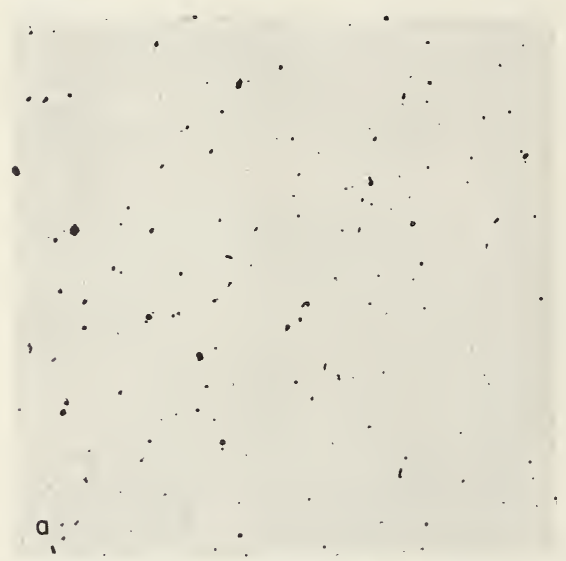

One criterion for obtaining true photographic records of the surface was that two overlapping areas taken at different exposure times and printed for maximum contrast showed inclusions common to both areas as the same size in both prints. The micrographs used were below the limit where overexposure could conceivably blot out smaller inclusions and reduce the size of larger ones. Furthermore, when sharp black inclusions were obtained against white backgrounds by contact printing, the print truly represented the negative. Finally, the print was visually checked against the sample. When these requirements had been satisfied, the micrographs were ready for computer analysis (figs. 1a and $1 \mathrm{~b}$ ).

Thirteen photomicrographs were processed. Six were of the longitudinal section and seven were of the cross section.

Longitudinal section. Photomicrographs were prepared at $50 \times, 100 \times$, and $200 \times$. The $50 \times$ magnification encompassed the width of the rod in two $5 \times 7$ photomicrographs. The higher magnifications showed more of the detail of the inclusion shapes, however, the $200 \times$ pictures were too high in magnification to give truly representative values. Accordingly, four $50 \times$ and two $100 \times$ pictures were chosen for examination. Since the computer analyzes a central area on the picture of only $42 \times 42 \mathrm{~mm}$, the pictures were chosen to give maximum, average, and minimum blackness wherever possible. The six pictures chosen were:

$50 \times$-maximum blackness $50 \times$-minimum blackness $50 \times$-average blackness $100 \times$-maximum blackness $50 \times$-average blackness $100 \times$-minimum blackness

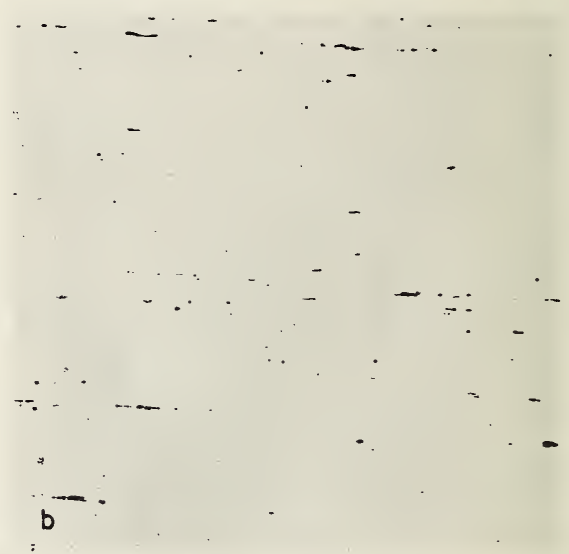

FIGURE 1. NBS 461 steel polished for inclusion counting and microprobe examination.

a. Cross section, unetched, $\times 100$

b. Longitudinal section, unetched, $\times 100$ 

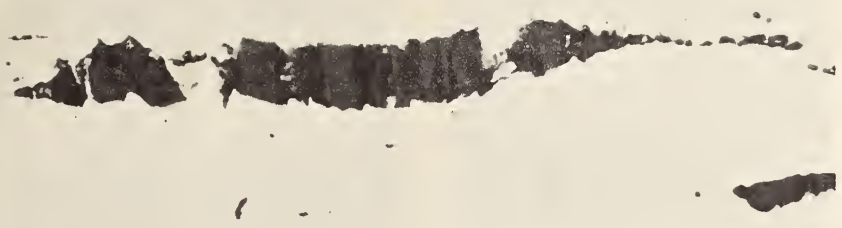

a
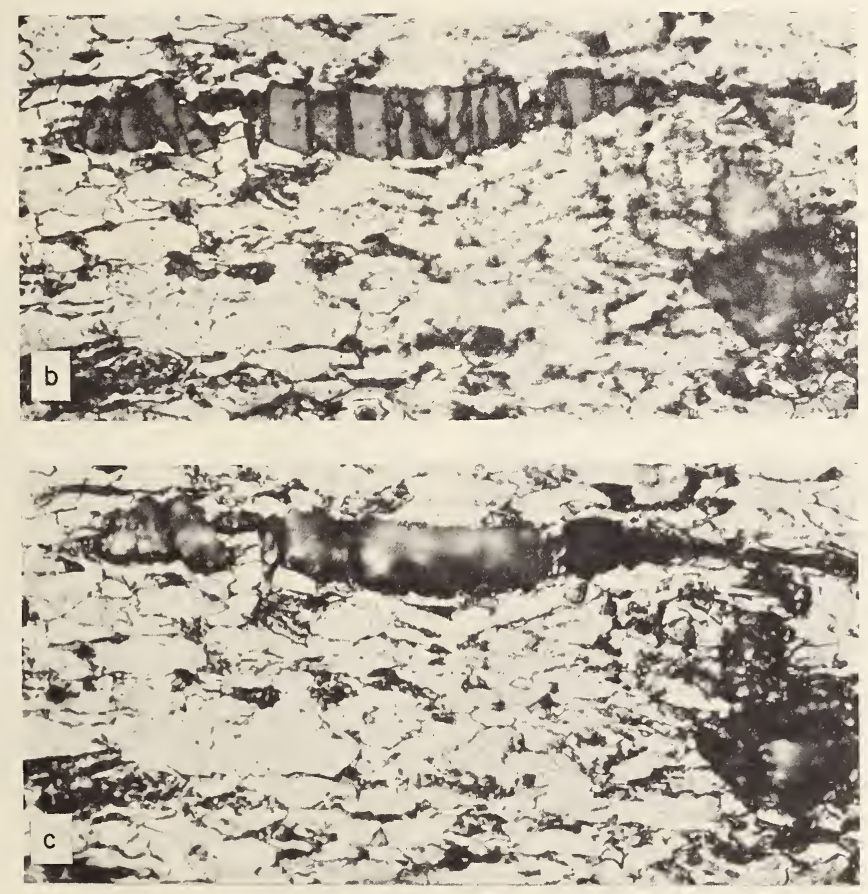

Figure 2. Typical inclusion in longitudinal section.

a. Unetched, $\times 1000$. Note the definite duplexity, i.e., discrete hars with smaller crystallites hetween.

b. Same inclusion after succesive etching for $10 \mathrm{~s}$ in 10 percent nital, 5 min in 10 percent aqueous chromic acid (neither of which attacked the inclusions), followed by $5 \mathrm{~min}$ in boiling alkaline sodium picrate, and $5 \mathrm{~min}$ in 5 percent alcoholic hydrochloric acid. Note attack by the sodium picrate on the small crystallites hetween hars and slight attack (lighter color) on hars by the bydrochloric acid, indicating presence of $\mathrm{FeO}$.MnO largely in the crystallites. $\times 1000$. c. Same as (b) except followed by $10 \mathrm{~min}$ in 20 percent aqueous hydrofluoric acid. Note nearly complete removal of hars indieating presence of $\mathrm{FeO} \cdot \mathrm{SiO}_{3}$. $\times 1000$, 
The computer was ordered to furnish the area of the inclusions. to display them on the oscilloscope, to slice the pictures horizontally and vertically, and to perform two lineal analyses of the pictures at right angles to each other.

Cross section. The area, display, slice, and lineal analyses were performed on seven pictures, six of which were at $100 \times$ and one at $50 \times$. The micrographs were taken such that the cross section was covered from one edge to nearly the other edge. The six $100 \times$ pictures represented three from the center and three from the edge. These were taken for maximum, average, and minimum blackness from each position. The $50 \times$ picture was randomly selected near the middle.

\subsection{Studies on Etched Structures}

Super picral, nital, and high-chlorine aqua regia failed to cut cleanly through all of the grain boundaries; however, a $3 \frac{1}{2}$ percent solution of concentrated $\mathrm{HNO}_{3}$ in water successfully performed this task. Etching time was 9 to 10 s with the sample immersed in the solution.

In addition to normal magnifications, the specimens were photographed, in some cases, at magnifications such that the statistics table printed out by the computer would classify the grain sizes directly into ASTM numbers. Since the computer program establishes $\sqrt{2}$ size classes on the basis of maximum bloh area. and ASTM Method E-112 [10] defines grain size values in terms of average grain areas, an adjustment by $\sqrt[4]{2}$ on diameters or $\sqrt[8]{2}$ on areas causes the two classifications to match. The adjustment factor was found to be nearly constant for each of the 30 listed ASTM classes. This factor is 0.925 , i.e., if one were doing a grain size count at $1000 \times$ by conventional methods, a photomicrograph taken at $925 \times$ and processed by the computer would give the same grain size. Based on these facts, photomicrographs were taken of both the longitudinal and cross sections at $462.5 \times, 500 \times, 925 \times$, and $1000 \times$. To increase the contrast, the $8 \times 10$ photographs were printed onto lithographic film and then printed onto high contrast photographic paper. This revealed the pearlite as white and the ferrite as black. Photomicrographs at $500 \times$ are shown in figures 3 and 4 . Computer analyses were made on portions of each photomicrograph except those of the longitudinal section taken at $925 \times$ and $1000 \times$.

For these analyses, the computer was ordered to state the area of ferrite (black), display the picture, slice horizontally and vertically, and to do lineal analyses at right angles to one another. On a photomicrograph of the cross section taken at $462.5 \times$, the computer was ordered to do a full blob analysis and report the results in the "Statistics" table. The information to be gained by these procedures is the ferrite percentage, the mean free path in microns for ferrite and pearlite, and the grain size. Furthermore, from the mean free path data and from the manner in which the photomicrographs were prepared, data for a grain size determination by the Heyn intercept method are available [10].

\section{Results}

\subsection{Homogeneity}

\section{a. Nickel in the Cross Section}

Microprobe analyses were made on three separate days. First, 15 random points on the sample were analyzed, and then two traces across the sample were made at right angles to one another on successive days. These traces contained 19 and 12 points respectively. Points taken just inside the edge of the sample gave results which were very different from results taken from points a millimeter or more away from the edge. There were nine such points, of which eight gave high results and one gave a low result. The latter probably can be explained by the fact that the beam overlapped into the mounting material. The edge was not maintained completely flat during polishing. This resulted in a higher $\mathrm{x}$-ray takeoff angle and caused the high results observed for the remaining eight points.

Due to the low nickel concentration and the low $x$-ray emergence angle in the NBS microanalyzer $\left(5.5^{\circ}\right)$, the $3 \sigma$ counting error was about $0.45 \mathrm{wt}$ percent. Table 2 shows the expected concentration ranges and the observed ranges after the edge affected points have been dropped.

TABLE 2. Nickel concentration in cross sections of NBS-461 steel*

\begin{tabular}{|c|c|c|c|c|}
\hline Run number & $\begin{array}{l}\text { Number of } \\
\text { points }\end{array}$ & $\begin{array}{l}\text { Expected } \\
\text { limits }\end{array}$ & $\begin{array}{l}\text { Observed } \\
\text { limits }\end{array}$ & $\begin{array}{l}\text { A verage } \\
\text { concentra- } \\
\text { tion }\end{array}$ \\
\hline $3_{3}$ & $\begin{array}{l}12 \\
15 \\
10\end{array}$ & $\begin{array}{c}\% \\
1.47-2.35 \\
1.30-2.19 \\
1.28-2.22\end{array}$ & $\begin{array}{c}\% \\
1.50-2.38 \\
1.33-2.12 \\
1.48-2.15\end{array}$ & $\begin{array}{l}\% \\
1.85 \\
1.74 \\
1.75\end{array}$ \\
\hline
\end{tabular}

"See Appendix [7] for complete data. error.

* Range shown is the certified value $(1.73 \%) \pm 3$ times the standard counting

\section{b. Iron in the Cross Section}

The observed range for the iron concentrations was 95.6 to 98.2 percent with an average of 97.0 percent. The iron concentration, by difference, based on the certificate is 96.5 percent. The largest deviation from the observed mean value is 1.44 percent. The appendix [7] contains the complete data.

\section{c. Nickel in the Longitudinal Section}

Two separate investigations were made; these consisted of 48 and 14 analyses respectively. Of the total of 62 points, 60 fell within the expected limits. The average concentration found for both investigations was 1.73 percent $\mathrm{Ni}$, which agrees with the certified value. The extreme edges were aroided. The complete data for the 62 random points investigated are shown in the appendix [7], while table 3 shows the expected and observed concentration ranges. 


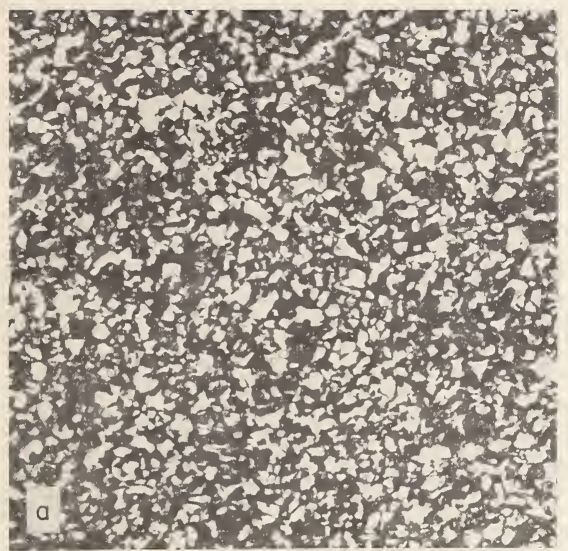

:70

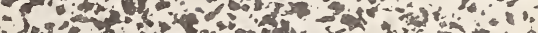

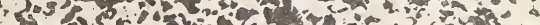

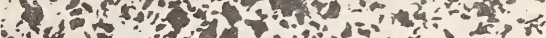
"i.

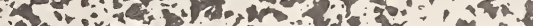
$3 \cos ^{4}$ end

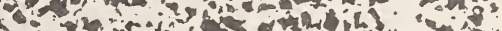

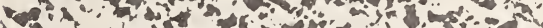

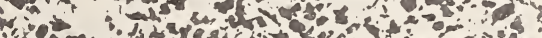

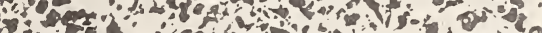

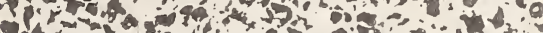

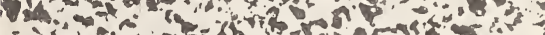

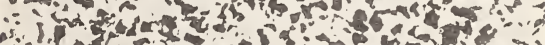

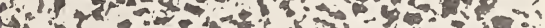

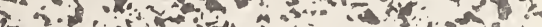
40, $;$ है

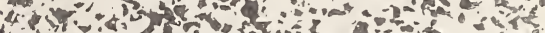

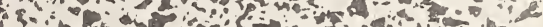

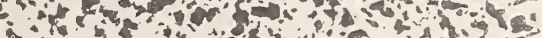

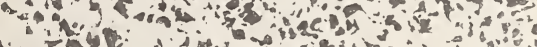

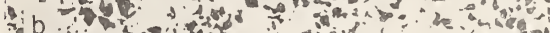

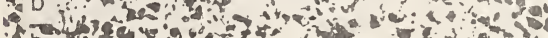

Figure 3. Cross section of NBS 461 steel etched for $9 \mathrm{~s}$ in $3-1 / 2$ percent $\mathrm{HNO}_{3}$

a. Ferrite white and pearlite black. $\times 500$

b. Same as (a) except ferrite black and pearlite white as scanned into the computer. $\times 500$
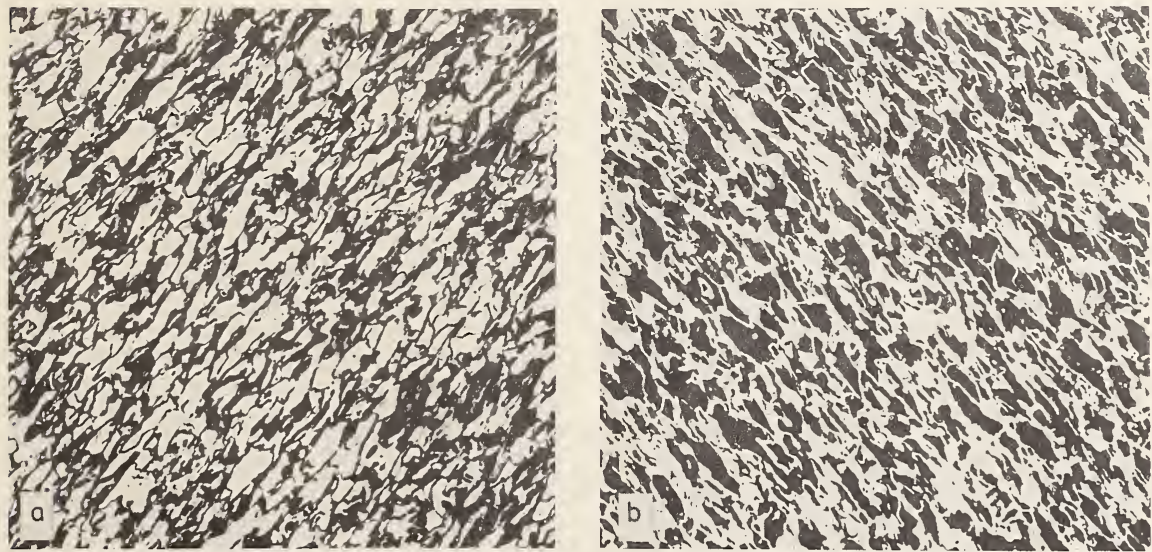

FIGURE 4. Longitudinal section of $N B S 461$ steel etched for $10 \mathrm{~s}$ in $3-1 / 2$ percent $\mathrm{HNO}_{3}$

a. Ferrite white and pearlite black. $\times 500$

b. Same as (a) except ferrite black and pearlite white as scanned into the computer. $\times 500$

d. Iron in the Longitudinal Section

Sixteen analyses were made at random points with the extreme edges being avoided. The observed concentration range was 93.0 to 98.6 percent with an average of 95.8 percent. Two points deviated from the mean by 2.9 percent; the next largest deviation was 1.6 percent. The appendix [7] contains the complete data. 
TABLE 3. Nickel concentration in longitudinal sections of NBS-461 steel

\begin{tabular}{c|c|c|c|c}
\hline Run number & $\begin{array}{c}\text { Number of } \\
\text { points }\end{array}$ & $\begin{array}{c}\text { Expected } \\
\text { limits }\end{array}$ & $\begin{array}{c}\text { Observed } \\
\text { limits }\end{array}$ & $\begin{array}{c}\text { Average } \\
\text { concentra- } \\
\text { tion }\end{array}$ \\
\hline & & $\begin{array}{c}\% \\
1.22-2.23\end{array}$ & $\begin{array}{c}\% \\
1.19-2.05\end{array}$ & $\begin{array}{c}\% \\
1.73 \\
1.73\end{array}$ \\
\hline
\end{tabular}

- One point in each run was too low.

\subsection{Inclusions in the Steel \\ a. Identification of the Inclusions}

The longitudinal section of the steel shows stringers which appear to be composites under the microscope. The structure appears somewhat similar to that observed in eutectoid type structures, i.e., barring occurs. These inclusions were investigated by means of the electron probe with the result that $\mathrm{Mn}$ and $\mathrm{Cr}$ were confirmed in them. There is no Ni present in the inclusions. There appeared to be $\mathrm{Fe}$, but this is indeterminate because the matrix is so rich in $\mathrm{Fe}$ and the distribution in depth of the inclusions is unknown.

An attempt was made to further identify the inclusions by progressive etching [11]. This scheme was followed until nearly all of the inclusion components had been removed or attacked, i.e., through a $10 \mathrm{~min}$ etch in aqueous 20 percent HF. Photomicrographs were taken of the same inclusion at each stage. Some of these are shown in figure 2. From the results it was concluded that: (1) The bars are largely $\mathrm{FeO} \cdot \mathrm{SiO}_{2}$, but they probably contain some $\mathrm{MnO} \cdot \mathrm{SiO}_{2}$ since the bars are slightly attacked by $5 \mathrm{~min}$ in 5 percent $\mathrm{HCl}$ in $\mathrm{C}_{2} \mathrm{H}_{5} \mathrm{OH}$. (2) The other components are probably $\mathrm{MnO} \cdot \mathrm{FeO}$ (note attack by $5 \mathrm{~min}$ in boiling alkaline sodium picrate) mixed with a carbide. It is surmised that the carbide is $\mathrm{Fe}-\mathrm{Cr}$ since the carbon bearing patches in the bulk of the steel behave in a like manner under polarized light to the crystallites remaining after the $\mathrm{FeO} \cdot \mathrm{SiO}_{2}$ bars have been removed by 20 percent HF. It may be that these are only an iron carbide and that the $\mathrm{Cr}$ is combined as oxide or carbide.

\section{b. Volume and Weight Percentages of Nonmetallic Inclusiong}

Longitudinal Section. The area percent of a random cut has been shown to be equal to the volume percent of the material [12]. Considering the previously established homogeneity of NBS-461 steel, it was believed that virtually any cut made on the random sample would be truly representative of the standard. Area results as given by the computer are then interpreted to be volume percent of inclusions in the steel. The average of four $50 \times$ pictures gave a volume percentage of inclusions equal to 0.40 . A single $100 \times$ picture chosen for average blackness (inclusion density) gave a volume percentage of 0.42 .

Cross Section. Two sets of photomicrographs were taken near the center and near the edge. These were processed by the computer as separate entities to determine whether any large gradients of inclusion density existed. For the set of three $100 \times$ pictures taken near the center of the sample, the volume percentage of inclusions was 0.38 percent. The three $100 \times$ pictures taken near the edge gave an average volume percentage of 0.42 percent. Obviously, no appreciable gradient was found, and the six pictures were then taken as representative of the entire cross section. This gave an average volume percentage of 0.40 percent. Note that this is the same result as that obtained for the longitudinal section. Data for each picture processed will be found in the Appendix [7].

\section{c. Estimation of the Weight Percent of Inclusions}

From the results, on both the longitudinal and cross sections it is reasonable to say that the inclusion content is 0.40 volume percent. For an approximate calculation of the weight percentage of the inclusions, equal portions of $\mathrm{FeO} \cdot \mathrm{SiO}_{2}$ and $\mathrm{FeO} \cdot \mathrm{MnO}$ can be assumed in the inclusion. The density of $\mathrm{FeO} \cdot \mathrm{SiO}_{2}$ is 3.5 while that of $\mathrm{FeO} \cdot \mathrm{MnO}$ is 5.6. The average density is then about 4.5. The density of the metallic portion of the steel is about 7.9. Then for the total density of the steel as issued:

$$
\begin{aligned}
& p=[(0.996)(7.9)+(0.004)(4.5)] \\
& p=7.8384+0.0180 \\
& p=7.8564
\end{aligned}
$$

Weight percent of inclusions of 50 percent $\mathrm{FeO} \cdot \mathrm{SiO}_{2}$ and 50 percent $\mathrm{FeO} \cdot \mathrm{MnO}$ is $0.0180 / 7.8564=0.23$ percent. Thus, 0.23 weight percent of inclusion is obtained. To obtain a better indication of the absolute range for the weight percentage of the inclusions, the value was computed by first assuming the inclusions to be only $\mathrm{FeO} \cdot \mathrm{SiO}_{2}$ and then to be only $\mathrm{FeO} \cdot \mathrm{MnO}$. The weight percent in the first case is 0.18 and in the second, 0.28 . It can thus be stated with confidence that the weight percentage of the inclusions is $0.23 \pm 0.05$.

\section{d. Estimation of Number and Size of Inclusions}

The computer was ordered to do a full statistical analysis on the average $100 \times$ picture taken of the cross section near the center. From this analysis, some estimation of the number and size of the inclusions can be made.

The statistics table indicated that the average height and width of the inclusions was equal and had a value of $5.25 \mu$. Furthermore, the mean value of the major axis of elliptical shapes was $6.0 \mu$. Based on this, it is possible to view the inclusions in the cross section as sections of an elliptical cylinder having a mean diameter of approximately $5.5 \mu$.

Data on the area distribution of the inclusions from the statistical analyses, coupled with the fact that at $100 \times$ the real area of metal represented by the photomicrograph is $0.176 \mathrm{~mm}^{2}$, enabled the calculation of the approximate number of inclusions per cubic millimeter of steel. This was first attempted 
by using the method of Bergh and Lindberg [13] which assumes that the inclusions are spherical. However, the summation of the predicted spherical volume of the inclusions was over 100 percent greater than the real volume as deduced by the computer. Therefore, the Bergh and Lindberg method was discarded.

Visual observation indicates that the inclusions in NBS-461 steel are cylindrical in shape. On this basis, an attempt was made to find the average length in terms of the diameter. Both mean free path data in the inclusions, and the statistical analyses of longitudinal and cross-sectional photomicrographs were used. The results from the former gave the length equal to 2.64 times the diameter, while the results from the latter gave the length as 2.73 times the diameter. For purposes of calculation, the length was taken as 2.7 times the diameter. The conversion of the number of inclusions in a given class per square millimeter to inclusions of the same class per cubic millimeter is then obtained by dividing by the particle length in millimeters. Since, for a $100 \times$ photomicrograph, the computer scans spots $2.5 \mu^{2}$, the smallest observable inclusion diameter is $2.5 \mu$, as compared with $10 \mu$ minimum diameter frequently reported.

The total number of inclusions per cubic millimeter was found to be about 14,000 of which 76 percent had diameters of $5 \mu$ or less. These 76 percent represent only about 20 percent of the total inclusion volume, however. The total inclusion volume percent was 0.44 from the photomicrograph in question; the calculated inclusion percentage was also 0.44 .

A table of probabilities for a $50 \mu$ spherical volume to contain one inclusion of each size observed was prepared. The $50 \mu$ spherical volume was chosen to be representative of the sample size for laser excitation sources and the solids mass spectrometer. Full data are shown in the Appendix [7].

\section{e. Mean Free Path Between Inclusions}

The computer delivered data on the mean free paths in both the inclusions and in the steel, as obtained from lineal analyses of the photomicrographs. In the cross section, the average mean free path within an inclusion was about $4.5 \mu$, while the average mean free path in the steel was about $1600 \mu$. From these figures the probability of a random $1 \mu$ electron probe touching any inclusion is only about one in 350 .

In the longitudinal section, the average mean free path in an inclusion was about $7 \mu$ while in the steel, it was about $2700 \mu$. Here the probability for a random $1 \mu$ electron probe to touch an inclusion is only about one in 380 . The fact that the mean free paths are smaller than the maximum dimensions of the inclusions is to be expected since the longest path through the inclusion will not always be the path chosen by the computer. Complete mean free path data for each picture processed will be found in the Appendix [7].

\subsection{Analysis of the Etched Structure in NBS-461
Steel}

\section{a. Ferrite and Pearlite Percentages}

It is readily apparent from the photomicrographs of the etched structure that this steel is extremely fine grained. This presents an immediate dilemma since a fairly large portion of the grain itself may be lost in etching to clean cut grain boundaries. Thus, the apparent ferrite percentage derived from a photomicrograph of the etched structure can be very much lower than the actual ferrite percentage. As an illustration for a steel with an ASTM grain size number of 6.0 , the average grain diameter is given as $45 \mu$ [10]. Etching a $1 \mu$ grain boundary into such a steel causes the loss of $1 / 45(1 / 2 \mu$ on each "side") or 2.2 percent of the grain diameter and 4.4 percent of the area. However, in a steel with ASTM grain size of say 13, the average grain diameter is about $4 \mu$ and etching a $1 \mu$ boundary into such a steel causes the loss of 25 percent of the grain diameter. The resulting area loss is about 44 percent.

The problem, then was to obtain the ferrite and pearlite percentages with and without the grain boundaries. Fortunately, this was possible with the computer display system. Each picture as scanned into the computer was displayed on a cathode ray tube and compared with the original. The sensitivity of the scanner was adjusted until all of the grain boundaries were clearly cut through; the area deduced by the computer under these conditions was the ferrite percentage in the etched condition. Then the pictures were redisplayed and the scanner sensitivity adjusted until the grain boundaries were apparently removed (this was when the calibrated bar chart gave an area value of nearly 14,112 bits). No particular encroachment on the pearlite areas could be discerned by visual comparison of the cathode ray tube and the actual photomicrograph. The area deduced by the computer under these conditions was considered to be the ferrite percentage in the "unetched" condition, i.e., the actual ferrite percentage in the steel.

In the etched condition, the average volume percent of ferrite was found to be 32.8 percent, while in the unetched condition, the average volume percent of ferrite was found to be 54.8 percent. From this, two things are apparent: etching this fine grained steel has reduced the apparent ferrite surfaces by more than 40 percent. Furthermore, the pearlite percentage seems very high for a steel containing 0.15 percent carbon. This high pearlite value is a result of the history of the steel especially the fact that it is not fully annealed. For an estimate of the pearlite percentage which would be apparent in a photomicrograph of the annealed structure, NBS-461 steel may be compared to an 8615 steel which has roughly the same composition. In 8615 steel, the eutectoid value is at approximately 0.65 percent carbon. From this, an approximate value of 23 percent pearlite would be expected. Thus, as a result of its history, the NBS-461 steel exhibits approxi- 
mately twice as much pearlite as would be anticipated in the fully annealed structure. Complete data on ferrite percentages in all pictures processed will be found in the Appendix [7].

\section{b. Mean Free Paths for Ferrite and Pearlite}

The computer was ordered to do lineal analyses on the steel in the etched condition. The average ferrite mean free path was found to be $1.63 \mu$ while the average pearlite mean free path was found to be $3.38 \mu$. From these data the probabilities for a $1 \mu$ electron probe to be in a given constituent can be computed. The probabilities are about one in five that the spot is in pure ferrite, one in five that it is in a ferrite-pearlite mixture, and three in five that it is in pure pearlite. With a $3.5 \mu$ electron probe, one is always in a mixture of ferrite and pearlite. Complete mean free path data on all pictures processed will be found in the Appendix [7].

\section{c. Grain Size of the Steel}

Despite the fact that the steel was in a worked condition, it was felt that a meaningful grain size could be deduced. Furthermore, with the aid of the computer, a number of individual grains could be analyzed separately and a histogram of ASTM grain classes in the steel could be established.

It was desired to state the grain size in both the etched and unetched conditions; the grain size deduced for the unetched condition is believed to be the more accurate statement for the real grain size. However, since one normally works with etched structures when using the ASTM grain size chart, it was deemed necessary to present both values. With both values available some idea of the effect of etching on the apparent ASTM grain size in a very fine grained steel could be indicated.

To obtain the grain size in the etched condition, the Heyn intercept procedure was adopted. The average intercept lengths required are the same as the mean free paths given by the computer. From these data, the number of grains per cubic millimeter may be calculated by the following relation [10].

where

$$
n_{1 t n}=(0.7)\left(n_{1}\right)\left(n_{t}\right)\left(n_{n}\right)
$$

$n_{1 \text { tn }}$ is the number of grains per cubic millimeter.

$n_{1}$ is the average number of grains per millimeter intercepted in the longitudinal direction.

$n_{t}$ is the average number of grains per millimeter intercepted in the transverse direction.

$n_{n}$ is the average number of grains per millimeter intercepted in the normal direction.

Since photomicrographs had been prepared from sections of the steel taken at right angles to one another and since rotations had been performed in the computer, all of the necessary data were available. The values for $n_{1}$ and $n_{t}$ were taken from the ferrite mean free path data in the longitudinal section while the $n_{n}$ value was taken from the ferrite mean free path data in the cross section. Duplicate grain size analyses were made on photomicrographs taken at $462.5 \times$ and $500 \times$. The latter are shown in figures 3 and 4 . The calculation made on the $462.5 \times$ picture will serve to illustrate.

$$
n_{1 t n}=(0.7)\left(n_{1}\right)\left(n_{t}\right)\left(n_{n}\right)
$$

Since $1 \mathrm{~mm}$ equals $1000 \mu$, the $n$ value is in general equal to:

$$
n=\frac{1000}{\text { mean free path (in microns) for ferrite }}
$$

In the $462.5 \times$ photomicrograph the mean free path values were $2.03 \mu$ in the longitudinal direction, $1.48 \mu$ in the transverse direction, and $1.98 \mu$ in the normal direction. Thus

$$
\begin{aligned}
& n_{1 t n}=(0.7)\left(\frac{1000}{2.03}\right)\left(\frac{1000}{1.48}\right)\left(\frac{1000}{1.98}\right) \\
& n_{1 t n}=117 \times 10^{6} \text { grains } / \mathrm{mm}^{3} .
\end{aligned}
$$

Since ASTM grain size 14 has $45.2 \times 10^{6}$ grains $/ \mathrm{mm}^{3}$ and grain size 15 has $128 \times 10^{6}$ grains $/ \mathrm{mm}^{3}$, it can be seen that the grain size in the etched condition is indicated to be 14.9. Precisely the same result is obtained when the mean free path data from the $500 \times$ photomicrographs are used.

To obtain the grain size in the unetched condition, mean free path data for the ferrite in the unetched condition were required. These data were obtained by using the ferrite area values obtained in the unetched condition in combination with the total number of lines found in the ferrite by the lineal analysis performed with the computer on the etched structure. The effect is to add the grain boundary back onto each grain. In our example for the $462.5 \times$ picture, the new mean free path values found were: $3.29 \mu$ in the longitudinal direction, 2.55 $\mu$ in the transverse direction, and $3.65 \mu$ in the normal direction. These values led to an $n_{1 t n}$ value of $22.9 \times 10^{6}$ grains per cubic millimeter corresponding to an ASTM grain size of 13.3 . When adjusted mean free path data were used in conjunction with the $500 \times$ photomicrographs, the ASTM grain size for the unetched condition was found to be 13.5 .

Virtually the same effect, i.e., the addition of the boundary area to the grain area, can be obtained by adding the perimeter of the etched grain to the area of the etched grain. To obtain an indication of the spread of grain sizes in this worked material, the computer was ordered to do a full statistical analysis, which includes the perimeter plus area data, on a photomicrograph of the cross section taken at $462.5 \times$. In this case it was hoped that all the grain boundaries were cleanly cut through since any connectivity will be found by the computer and treated as one unit. Of a total of 356 blobs analyzed by the computer, only about 30 exhibited this type of complexity as evidenced by a second peak in the histogram of frequency versus ASTM grain size. 
The histogram is presented in figure 5 . The peaks associated with the very small grain sizes are ferrite particles in the pearlite while the larger grain sizes are due to the previously mentioned complex grains. The estimated Gaussian distribution curve is also shown. From this figure, the mean ASTM grain size is 13.2 .

Thus, in the etched condition, the apparent rounded ASTM grain size is 15 while in the unetched condition, the average grain size is 13.2 to 13.5 . The significant size range indicated by the Gaussian distribution is about ASTM size 12.5 to ASTM size 15.5. It is interesting to note that there are about two thousand grains for each inclusion.

\section{Discussion}

It has been found that NBS-461 steel is homogeneous in both nickel and iron at 2 to $4 \mu$ levels by means of electron probe microanalysis. These results have been corroborated by Adler $^{3}$ who made 10 determinations each for nickel and iron in the cross section of the steel using a $1 \mu$ electron probe. The maximum volume of steel excited was assumed to be about $7 \mu^{3}$ (a hemisphere $3 \mu$ in diameter). This corresponds to about $5 \times 10^{-11} \mathrm{~g}$ of steel per determination. The average of a number of determinations for nickel and iron in both the cross section and the longitudinal section was in close agreement with the certified value of 1.73 percent for nickel and with the predicted value for iron (by difference) of 96.5 percent.

The operator of an electron probe microanalyzer can easily avoid visible inclusions; even if he could not, the probability for striking an inclusion with a $1 \mu$ probe is only one in 350 . Furthermore, if the $\mathrm{x}$-ray path from the sample is assumed to pass through a $20 \mu^{3}$ hemisphere of steel before the $\mathrm{x}$ rays emerge from the surface, the probability for an underlying inclusion to be anywhere in the x-ray path is less than 3 in 100.

The steel has been shown to be structurally homogeneous at a $5 \mu$ level since the mean free path in ferrite is $1.63 \mu$ while the mean free path in pearlite is $3.38 \mu$. Thus, any $5 \mu$ probe will be in a structurally homogeneous region. Furthermore, other metallographic observations have shown that there is no long range inhomogeneity in the structures. On this basis it is felt that at a $5 \mu$ level, the structural homogeneity predicts that the other elements in NBS-461 steel, except those concentrated in the inclusions, will be uniformly distributed.

It is reasonable to expect partition of some elements between ferrite and carbide (or in pearlite). For example, manganese, phosphorus, sulfur, and silicon are known to concentrate in ferrite areas while chromium, vanadium, niobium, tungsten, and tantalum are known to have an affinity for carbide regions. Therefore, at less than the $5 \mu$ structural homogeneity level, these elements might well give fluctuations in analysis.

\footnotetext{
I. Adler, private communication (1963).
}

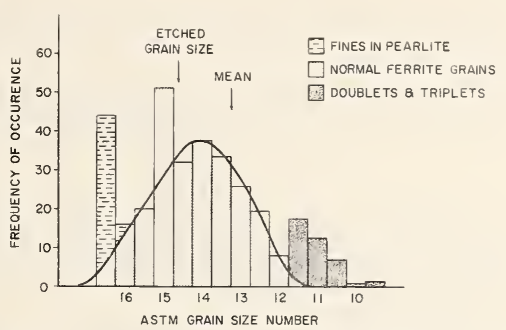

FIgure 5. Histogram of ASTM grain size numbers in NBS 461 steel.

The etched grain size is 14.9 and the mean unetched grain size is 13.5 .

For other microanalytical techniques, a $50 \mu$ sphere was assumed to be a representative sample. This corresponds to about 0.52 microgram of the steel or about ten thousand times the amount investigated by means of electron probe microanalysis. Since it takes about four inclusions of average size to make a 1 percent discrepancy in weight, such an occurrence is highly unlikely.

A commonly found grain size in many steels corresponds to ASTM number 5.5 or 6.0 . In this case, the $50 \mu$ spherical volume would sample only one or two grains. However, it has been shown that the average grain size of NBS $\div 461$ steel corresponds to ASTM number 13.5. The resultant average number of grains in the $50 \mu$ sphere is about three thousand-certainly a fair sampling for an analysis.

It is believed that the homogeneity level of this steel corresponds very closely to the grain size. In this case, the fine grain size was achieved by the addition of rare earths, aluminum, and other beneficial elements. Extensive cold-working was followed by a final process anneal just sufficient to produce recrystallization without grain growth.

It can be confidently stated that the homogeneity level in NBS-461 steel is such that present day microanalytical techniques can be carried out with little fear of discrepancies due to inhomogeneity.

\section{Summary of Results on NBS-461 Steel}

\subsection{Homogeneity}

Nickel. 108 separate $\mathrm{Ni}$ determinations were made with the microprobe (2-4 $\mu$ spot). Of these only two fell outside of $3 \sigma$ limits predicted by the number of counts. The longitudinal, transverse and normal directions were examined. The average analysis was 1.73 percent $\mathrm{Ni}$ which agrees with the certificate value.

Iron. 25 separate iron determinations were made. Again all three directions were examined. The largest deviation from the mean was 2.9 percent. The average analyses were 95.8 percent iran in the 
longitudinal section and 97.0 percent iron in the cross section. The certificate value (by difference) is 96.5 percent $\mathrm{Fe}$.

Other Elements. Probably homogeneous at $5 \mu$ levels except for those contained in the inclusions.

\subsection{Inclusions}

Identification: Both the microprobe and chemical etching tests were used. The inclusions were identified as consisting of $\mathrm{FeO} \cdot \mathrm{SiO}_{2}$ and $\mathrm{FeO} \cdot \mathrm{MnO}$. Some $\mathrm{Cr}$ is also present in a combined form.

Volume percentage: 0.40

Weight percentage: $0.23 \pm 0.05$ (assumed equal portions of $\mathrm{FeO} \cdot \mathrm{SiO}_{2}$ and $\mathrm{FeO} \cdot \mathrm{MnO}$ on a weight basis).

Mean free path in inclusion: $4.7 \mu$ (cross section); $7 \mu$ (longitudinal section) $; 5.75 \mu$ average.

Mean free path in steel: $1600 \mu$ (cross section); $2700 \mu$ (longitudinal section); $2100 \mu$ average.

Number of inclusions per cubic millimeter: 14,000 (approx.).

Probability for random one micron probe to strike a surface inclusion: 1 in 350 .

Probability for $\mathrm{x}$ rays from a microprobe to strike an underlying inclusion: 1 in 34 .

Probability for an inclusion to affect an analysis of a $50 \mu$ sphere of steel by 1 percent: Negligible.

Inclusion shape: Rod with average length equal to 2.7 times the average diameter.

\subsection{Characteristics of the Steel}

Ferrite percentage: 54.8

Apparent ferrite percentage after etching: 32.8 Mean free ferrite path: $1.63 \mu$

Mean free pearlite path: $3.38 \mu$ (thus a $3.5 \mu$ spot must always be in a mixture; a $1 \mu$ spot has a one in five probability of being in pure ferrite and a three in five probability of being in pearlite).

Average ASTM grain size in etched condition: 14.9 (by Heyn method).
Average ASTM grain size in unetched condition: 13.5 (Heyn and particle area methods).

Average ferrite grain diameter (unetched): $3.5 \mu$.

\section{References}

[1] Standard materials issued by the National Bureau of Standards, NBS Misc. Publ. 241 (1962).

[2] J. R. Cuthill, L. L. Wyman, and H. Yakowitz, Metallurgical microanalysis with the electron probe, J. Metals 15 (1963), in press.

[3] J. Philibert, The Castaing "Microsonde" in Metallurgical and mineralogical research, J. Inst. Metals 90, 241 (1962).

[4] L. S. Birks, Calculation of x-ray intensities from electron probe specimens, J. Appl. Phys. 32, 387 (1961).

[5] D. M. Poole and P. M. Thomas, Quantitative electron probe microanalysis, J. Inst. Metals 90, 228 (1962).

[6] M. J. Henoc, Contribution to electron probe microanalysis, French Postal and Telecommunications Ministry, Study number 655 "P.C.M." 38 pp. (1962) (a translation by H. Yakowitz (1963) is available for distribution).

[7] R. E. Michaelis, H. Yakowitz, and G. A. Moore, Appendix to Metallographic Characterization of an NBS Spectrometric Low-Alloy Steel Standard (available on request).

[8] G. A. Moore, L. L. Wyman, and H. M. Joseph, Chapter 15 in Quantitative Metallography, F. N. Rhines, Ed. (McGraw-Hill Book Co., Inc., New York, N.Y.) in press.

[9] G. A. Moore and L. L. Wyman, Quantitative metallography with a digital computer: Application to a Nb-Sn superconducting wire, J. Res. NBS 67A (Phys. and Chem.) No. 2, 127 (1963).

[10] Standard methods for estimating the average grain size of metals, ASTM Designation E-112 (revised 1963) $18 \mathrm{pp}$.

[11] Nonmetallic inclusions in steel, Metals Handbook, American Society for Metals 1948, 445-452.

[12] A. E. Delesse, Recherches sur les Roches Globuleures, Proc. Soc. de Geologie de France, Mem. 4, 67 (1952).

[13] S. Bergh and O. Lindberg, On the microscopic determination of the number and distribution of nonmetallie inclusions, Jernkontorets Annaler 146, 862 (1962) [Henry Brutcher Translation No. 5772-7 pp. (1963)].

[14] A. Taylor, X-ray Metallography (J. Wiley and Sons, Inc., New York, 1961) table 73, pp. 936-943.

[15] L. S. Birks, Fluorescent x-ray excitation efficiencies, Spectrochimica Acta 17, 148 (1961). 


\section{APPENDIX \\ to \\ "Metallographic Characterization of an NBS \\ Spectrometric Low-Alloy steel Standard"}

by

R. E. Michaelis, H. Yakowitz, and G. A. Moore

Introduction:

This Appendix contains typical calculations and tabulated observational data referred to in the above titled publication, which appears in Volume 68A, page 343 of the National Bureau of Standards Journal of Research. Explanations of the use made of these data will be found in that publication.

Definition of Symbols:

\section{Section A-1}

$$
\begin{aligned}
\mu / \rho= & \text { mass absorption coefficient } \\
\theta= & \mathrm{X}-\mathrm{ray} \text { take off angle } \\
\chi= & \mu / \rho \text { Cosec } \\
\mathrm{h}= & \text { constant } \mathrm{A} / \mathrm{Z}^{2} \text {, where } \mathrm{A} \text { is } \\
& \text { the atomic weight, and } \mathrm{Z} \text { is the } \\
& \text { atomic number } \\
\mathrm{K}_{\mathrm{A}}= & \text { intensity of line for spec } \perp \text { men } \\
& \text { intensity of line for standard, } \\
& \text { where the standard is pure A } \\
\sigma= & \text { Lenard coefficient for electrons } \\
\mathrm{C}= & \text { Concentration in weight percent } \\
\mathrm{K}_{\mathrm{f}}= & \text { increment of radiation from ele- } \\
& \text { ment A due to fluorescence from } \\
\mathrm{E}= & \text { Element } \mathrm{B} \text { Excitation efficiency for fluor- } \\
& \text { escence } \\
\mathrm{Vo}= & \mathrm{K} \text { excitation voltage }(\mathrm{kV}) \\
\mathrm{V}= & \text { operating voltage (kV) }
\end{aligned}
$$

\section{Section A-2}

$\mathrm{C}=$ Concentration in weight percent

Sections A-3 and A-4

$\sigma=$ Standard deviation of the associated quantity, as determined by computer analysis of the internal variance of the image observed during the determination

\section{APPENDIX}

A-1 Absorption Correction (Philibert) ${ }^{*}$ for Electron Probe Microanalyzer Data

For iron:

$$
(\mu / \rho)_{\mathrm{Fe}}^{\mathrm{Fe}}=67.3^{* *} ;(\mu / \rho)_{\mathrm{Alloy}}^{\mathrm{Fe}}=69.3
$$

$$
\begin{aligned}
\theta & =5.5^{\circ} ; \operatorname{Csc} \theta=10.43 \\
(\chi)_{\text {alloy }} & =722 ; \quad(\chi)_{\mathrm{Fe}}=701 \\
\mathrm{~h}_{\mathrm{alloy}} & =\mathrm{h}_{\mathrm{Fe}}=0.083 \\
\sigma_{32.5 \mathrm{keV}} & =1550 \\
\mathrm{C}_{\mathrm{Fe}} & =1.001 \mathrm{k}_{\mathrm{Fe}} \text { for absorption }
\end{aligned}
$$

For nickel:

$$
\begin{aligned}
(\mu / \rho)_{\mathrm{Ni}}^{\mathrm{Ni}} & =56.2 ; \quad(\mu / \rho)_{a l l o y}^{\mathrm{Ni}}=354 \\
(\chi)_{\text {alloy }} & =3700 ; \quad(\chi)_{\mathrm{Ni}}=586 \\
\mathrm{~h}_{\text {alloy }} & =0.083 ; \mathrm{h}_{\mathrm{Ni}}=0.090 \\
\sigma & =1550 \\
\mathrm{C}_{\mathrm{Ni}} & =2.86 \mathrm{k}_{\mathrm{Ni}}
\end{aligned}
$$

Fluorescence correction: (Birks) ${ }^{* * *}$

For iron being fluoresced by $1.73 \% \mathrm{Ni}$

$$
\begin{aligned}
& \mathrm{K}_{\mathrm{f}}=\frac{(\mu / \rho)_{\mathrm{Fe}}^{\mathrm{Ni}}}{(\mu / \rho)_{\mathrm{alloy}}^{\mathrm{Ni}}} \cdot 0.6 \cdot \mathrm{C}_{\mathrm{Ni}} \mathrm{E}_{\lambda Z-\mathrm{Ni}} \frac{\left(\mathrm{V}-\mathrm{Vo}_{\mathrm{Ni}}\right)^{2}}{\left(\mathrm{~V}-\mathrm{Vo}_{\mathrm{Fe}}\right)^{2}} \\
& \mathrm{E}_{\lambda \mathrm{Z}-\mathrm{Ni}} \text { is the excitation efficiency for } \\
& \mathrm{Ni}-\mathrm{K} \alpha \text { photons to excite } \mathrm{Fe}-\mathrm{K} \alpha \\
& \text { photons at } \lambda=1.65 \mathrm{~A}^{\circ}(\mathrm{Ni}-\mathrm{K} \alpha) \text {. } \\
& \text { The value is } 21 \% \text { using data from } \\
& \text { Birks. }
\end{aligned}
$$

Vo is the $\mathrm{K}$ series excitation voltage $(\mathrm{kV})$

$\mathrm{V}$ is the operating voltage $(\mathrm{kV})$

$\mathrm{K}_{\mathrm{f}}=\frac{(362.5)}{353.6}(0.6)(0.0173)(0.21) \frac{[585.6]}{695.2}$

* Journal of Research, National Bureau of Standards, 68A, 343 (1964), reference [3].

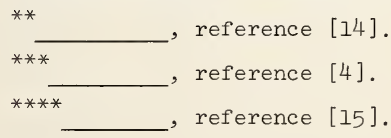


$\mathrm{K}_{\mathrm{f}}=0.002$

$1+K_{f}=1.002$

$\mathrm{C}_{\mathrm{Fe}}=\mathrm{k}_{\mathrm{Fe}} \frac{(1.001)}{(1.002)} \longrightarrow$ absorption

$\mathrm{C}_{\mathrm{Fe}}=0.999 \mathrm{k}_{\mathrm{Fe}}$

A-2 Actual Data Points From the Electron Probe Microanalyzer

(1) Cross-section

Nickel

$\begin{array}{cccc}\text { Run No. } & \text { Point } & \mathrm{k}(\%) & \mathrm{C}(\%) \\ \text { I } & 1 & 0.559 & 1.60 \\ \text { I } & 2 & 0.653 & 1.80 \\ \text { I } & 3 & 0.772 & 2.21 \\ \text { I } & 4 * & 0.861 & 2.46 \\ \text { I } & 5 & 0.703 & 2.01 \\ \text { I } & 6 & 0.574 & 1.64 \\ \text { I } & 7 & 0.663 & 1.89 \\ \text { I } & 8 & 0.833 & 2.38 \\ \text { I } & 9 & 0.714 & 2.04 \\ \text { I } & 10 & 0.744 & 2.13 \\ \text { I } & 11 * & 0.507 & 1.45 \\ \text { I } & 12 & 0.635 & 1.81 \\ \text { I } & 13 & 0.524 & 1.50 \\ \text { I } & 14 & 0.655 & 1.87 \\ \text { I } & 15^{*} & 0.479 & 1.37 \\ \text { II } & 1 & 0.532 & 1.52 \\ \text { II } & 2 & 0.510 & 1.46 \\ \text { II } & 3 & 0.466 & 1.33 \\ \text { II } & 4 & 0.584 & 1.67 \\ \text { II } & 5 & 0.646 & 1.85 \\ \text { II } & 6 & 0.675 & 1.93 \\ \text { II } & 7 & 0.670 & 1.91 \\ \text { II } & 8 & 0.678 & 1.94 \\ \text { II } & 9 & 0.769 & 2.20 \\ \text { II } & 10 * & 0.823 & 2.35 \\ \text { II } & 11 * & 0.771 & 2.20 \\ \text { II } & 12^{*} & 0.848 & 2.42 \\ \text { II } & 13 & 0.742 & 2.12 \\ \text { II } & 14 & 0.648 & 1.85 \\ \text { II } & 15 & 0.557 & 1.59 \\ \text { II } & 16 & 0.641 & 1.83 \\ \text { II } & 17 & 0.562 & 1.61 \\ \text { II } & 18 & 0.584 & 1.67 \\ \text { II } & 19 & 0.655 & 1.87 \\ \text { III } & 1 & 0.528 & 1.51 \\ \text { III } & 2 & 0.562 & 1.61 \\ \text { III } & 3 & 0.663 & 1.89 \\ \text { III } & 4 & 0.671 & 1.92 \\ \text { III } & 5 * & 0.718 & 2.05 \\ \text { III } & 6 * & 1.13 & 3.23 \\ \text { III } & 7 & 0.965 & 2.76 \\ \text { III } & 8 & 0.754 & 2.15 \\ \text { III } & 9 & 0.609 & 1.74 \\ \text { III } & 10 & 0.536 & 1.53 \\ \text { III } & 12 & 0.565 & 1.61 \\ \text { III } & & & 1.48 \\ & & & \end{array}$

Iron

$\begin{array}{crr}\text { Point } & \mathrm{k}(\%) & \mathrm{C}(\%) \\ 1 & 0.956 & 95.5 \\ 2 & 0.966 & 96.5 \\ 3 & 0.978 & 97.7 \\ 4 & 0.956 & 95.5 \\ 5 & 0.981 & 98.0 \\ 6 & 0.982 & 98.1 \\ 7 & 0.980 & 97.9 \\ 8 & 0.978 & 97.7 \\ 9 & 0.959 & 95.8\end{array}$

(2) Iongitudinal section Nickel

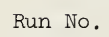




\begin{tabular}{|c|c|c|c|}
\hline Run No. & Point & $\mathrm{k}(\%)$ & $\mathrm{C}(\%)$ \\
\hline $\begin{array}{l}\text { II } \\
\text { II } \\
\text { II } \\
\text { II } \\
\text { II }\end{array}$ & $\begin{array}{l}1 \\
2 \\
3 \\
4 \\
5\end{array}$ & $\begin{array}{l}0.712 \\
0.635 \\
0.566 \\
0.549 \\
0.664\end{array}$ & $\begin{array}{l}2.03 \\
1.81 \\
1.62 \\
1.57 \\
1.90\end{array}$ \\
\hline $\begin{array}{l}\text { II } \\
\text { II } \\
\text { II } \\
\text { II } \\
\text { II }\end{array}$ & $\begin{array}{r}6 \\
7 \\
8 \\
9 \\
10\end{array}$ & $\begin{array}{l}0.702 \\
0.665 \\
0.624 \\
0.548 \\
0.647\end{array}$ & $\begin{array}{l}2.01 \\
1.90 \\
1.78 \\
1.57 \\
1.85\end{array}$ \\
\hline $\begin{array}{l}\text { II } \\
\text { II } \\
\text { II } \\
\text { II }\end{array}$ & $\begin{array}{l}11 \\
12 \\
13 \\
14\end{array}$ & $\begin{array}{l}0.444 \\
0.588 \\
0.594 \\
0.565\end{array}$ & $\begin{array}{l}1.27 \\
1.68 \\
1.70 \\
1.61\end{array}$ \\
\hline \multicolumn{4}{|c|}{ Iron } \\
\hline . & Point & $\mathrm{k}(\%)$ & $\mathrm{C}(\%)$ \\
\hline & $\begin{array}{l}1 \\
2 \\
3 \\
4\end{array}$ & $\begin{array}{l}0.945 \\
0.954 \\
0.953 \\
0.931\end{array}$ & $\begin{array}{l}94.4 \\
95.3 \\
95.2 \\
93.0\end{array}$ \\
\hline & $\begin{array}{l}5 \\
6 \\
7 \\
8\end{array}$ & $\begin{array}{l}0.950 \\
0.961 \\
0.945 \\
0.963\end{array}$ & $\begin{array}{l}95.0 \\
96.0 \\
94.4 \\
96.2\end{array}$ \\
\hline & $\begin{array}{r}9 \\
10 \\
11 \\
12\end{array}$ & $\begin{array}{l}0.974 \\
0.954 \\
0.967 \\
0.971\end{array}$ & $\begin{array}{l}97 \cdot 3 \\
95 \cdot 3 \\
96.6 \\
97.0\end{array}$ \\
\hline & $\begin{array}{l}13 \\
14 \\
15 \\
16\end{array}$ & $\begin{array}{l}0.958 \\
0.964 \\
0.987 \\
0.971\end{array}$ & $\begin{array}{l}95.7 \\
96.3 \\
98.6 \\
97.0\end{array}$ \\
\hline
\end{tabular}

A-3 Volume Percentage of Inclusions and Mean Free Paths in the Longitudinal Section as Deduced by Computer

Average mean free path* in

Picture $\operatorname{Vol}(\%)$ $\sigma$ inclusions

Mean<smiles>[CH]</smiles>$$
50 \mathrm{X}
$$

average

blackness

$\begin{array}{llll}50 X & 0.94 & 0.11 & 10.7 \\ \text { maximum } & & & \end{array}$

$\begin{array}{llll}\begin{array}{l}50 \mathrm{X} \\ \text { average }\end{array} & 0.19 & 0.05 & 7.38 \\ \text { blackness } & & & \end{array}$

$\begin{array}{cccc}\begin{array}{c}50 X \\ \text { minimum }\end{array} & 0.16 & 0.04 & 6.90 \\ \text { blackness } & & & \\ \begin{array}{c}\text { loox } \\ \text { average }\end{array} & 0.42 & 0.10 & 4.99 \\ \text { blackness } & & & \\ \begin{array}{c}\text { loox } \\ \text { minimum } \\ \text { blackness }\end{array} & 0.09 & 0.02 & 3.28 \\ & & & \end{array}$

2480

1392

4275

3435

1155

3264
Average mean free path* in

Mean

$\frac{\text { Picture }}{50 \mathrm{Xol}(\%)} \frac{\sigma}{0.405} \frac{\text { inclusions }}{8.36} \frac{\text { in steel }}{2896}$ average

$\begin{array}{cccc}\begin{array}{c}\text { loox } \\ \text { average }\end{array} & 0.26 & 4.14 & 2210 \\ \begin{array}{c}\text { All } \\ \text { average }\end{array} & 0.36 & 6.96 & 2667\end{array}$

As the 50X pictures may fail to resolve inclusions whose minimum dimension is much less than 5 microns, the mean free path between inclusions can be expected to be somewhat greater in the $50 \mathrm{X}$ pictures than in the 100X pictures. The lo0X series does not include an example of a maximum blackness area, hence the average Vol. \% of the two 100X pictures does not represent average material.

\footnotetext{
* Mean free paths are in microns and are the averages of two lineal analyses done at right angles to one another.

Volume Percentage of Inclusions and Mean Free Paths in the Cross-Section as Deduced by the Computer
}

Average
mean free
path* in

Mean

Picture $\operatorname{Vol}(\%)$ $\sigma$ inclusions free path$$
100 \mathrm{X}
$$$$
0.60
$$$$
0.08
$$$$
5.45
$$

in steel

middle

maximum

$$
100 \mathrm{X}
$$

$$
0.44
$$$$
0.06
$$

5.12

1132

middle

average

free path

$100 \mathrm{x}$

$$
0.11
$$

0.02

3.63

3062

minimum

$$
100 \mathrm{X}
$$

edge

$0.52 \quad 0.07 \cdot 4.98$

935

maximum

$$
100 \mathrm{X}
$$

edge

0.50

0.06

4.25

average

$$
\begin{aligned}
& \text { loox } \\
& \text { edge }
\end{aligned}
$$

minimum

$50 \mathrm{X}$

$$
0.19
$$

0.03

6.75

888

Average

( 3 middle) Average 0.42
( 3 near
edge)

Average

0.40

4.40

1336

Average all

p'ictures
0.37

4.74

1636 
Note the similarity of the $100 \mathrm{x}$ value to the value obtained for the longitudinal section.

As the 50X pictures do not show the effects of inclusions less than 5 microns in diameter, which amount to about $42 \%$ of the total count (Section A-7), the mean free path between inclusions may be expected to be abnormally long, and the apparent volume percent abnormally small.

* Mean free paths are in microns

A-4 Apparent Ferrite Volume Percentage in NBS 461 Steel in Both the Etched and Unetched Condition

\begin{tabular}{|c|c|c|c|}
\hline & Vol (\%) & & $\operatorname{Vol}(\%)$ \\
\hline Picture & (etched) & $\sigma$ & (unetched) \\
\hline
\end{tabular}

Cross-section

462.5X (area I)

$29.5 \quad 0.55 \quad 59.7^{*}$

Cross-section

462.5X (area II) $32.0 \quad 0.55 \quad 59.7^{*}$

$\begin{array}{llll}\begin{array}{l}\text { Cross-section } \\ \text { 500X }\end{array} & 34.1 & 0.54 & --- \\ \begin{array}{l}\text { Cross-section } \\ 925 \mathrm{X}\end{array} & 34.95 & 0.73 & 58.5 \\ \begin{array}{l}\text { Cross-section } \\ \text { loo0X }\end{array} & 34.2 & 0.62 & 54.4 \\ \begin{array}{l}\text { Longitudinal } \\ \text { section 462.5X }\end{array} & 34.5 & 0.67 & 56.0 \\ \begin{array}{l}\text { Longitudinal } \\ \text { section 500X }\end{array} & 30.7 & 0.89 & 50.2 \\ \text { Average } & 32.8 & 0.27 & 54.8 * *\end{array}$

*The unetched ferrite percentage is deduced from the perimeter plus area data in the statistics print out from the computer for the $462.5 \mathrm{X}$ cross-section photomicrographs
** The average ferrite percentage in the unetched condition excludes the $462.5 \mathrm{X}$ cross-section photomicrographs

A-5 Mean Free Path Data for Ferrite and Pearlite in NBS 461 Steel

\begin{tabular}{|c|c|c|c|c|c|c|}
\hline Picture & $\begin{array}{l}\text { Mean free } \\
\text { path* in } \\
\text { ferrite } \\
\text { (normal) } \\
\end{array}$ & $\begin{array}{c}\text { Mean free } \\
\text { path in } \\
\text { ferrite } \\
\text { (rotated } 90^{\circ} \text { ) }\end{array}$ & $\begin{array}{l}\text { Average mean } \\
\text { free path in } \\
\text { ferrite }\end{array}$ & $\begin{array}{l}\text { Mean free } \\
\text { path in } \\
\text { pearlite } \\
\text { (normal) } \\
\end{array}$ & $\begin{array}{c}\text { Mean free } \\
\text { path in } \\
\text { pearlite } \\
\text { (rotated } 90^{\circ} \text { ) }\end{array}$ & $\begin{array}{l}\text { Average mean } \\
\text { free path in } \\
\text { pearlite } \\
\end{array}$ \\
\hline $\begin{array}{l}\text { Cross-section } \\
462.5 \mathrm{X} \text { (area I) }\end{array}$ & 1.98 & 1.89 & 1.93 & 4.73 & 4.51 & 4.62 \\
\hline $\begin{array}{l}\text { Cross-section } \\
462.5 \mathrm{X} \text { (area II) }\end{array}$ & 2.11 & 1.99 & 2.05 & 4.49 & 4.25 & 4.37 \\
\hline $\begin{array}{l}\text { Cross-section } \\
500 \mathrm{X}\end{array}$ & 2.12 & 2.06 & 2.10 & 4.10 & 3.99 & 4.05 \\
\hline $\begin{array}{l}\text { Cross-section } \\
925 \mathrm{X}\end{array}$ & 0.968 & 0.919 & 0.943 & 1.80 & 1.71 & 1.75 \\
\hline $\begin{array}{l}\text { Cross-section } \\
1000 \mathrm{X}\end{array}$ & 0.913 & 0.880 & 0.895 & 1.76 & 1.70 & 1.72 \\
\hline $\begin{array}{l}\text { Longitudinal } \\
\text { section } 467.5 \mathrm{X}\end{array}$ & 2.03 & 1.48 & 1.75 & 3.84 & 2.81 & 3.33 \\
\hline $\begin{array}{l}\text { Longitudinal } \\
\text { section } 500 x\end{array}$ & 1.98 & 1.44 & 1.71 & 4.46 & 3.25 & 3.85 \\
\hline Average & 1.73 & 1.52 & 1.63 & 3.60 & 3.17 & 3.38 \\
\hline
\end{tabular}

* All mean free path data in microns

A-6 Number of Inclusions per Cubic Millimeter

This determination is based on cross-section photomicrographs of an area of average blackness.

For a micrograph at $100 \mathrm{x}$, the observed image field represents 0.1764 square millimeters on the specimen. Thus the indicated number of inclusions in a 1 square millimeter field is $\frac{1}{0.1764}=5.668$ times the number actually counted. 
The typical inclusion was determined to be a cylinder whose length perpendicular to the field is 2.7 times its mean diameter. For this shape, the observed sections may be assumed to be true sections rather than the reduced sections which would be observed for spheroids.

If the cubic millimeter were subdivided into 1000 plain slices each 1 micron thick, each inclusion would appear in a number of slices, this number being on the average the same as the length of the inclusions. Thus for size class 0 , each inclusion would be seen on 6.75 slices, but only $0.675 \%$ of all of the inclusions in one cubic millimeter are seen on one slice. The number of inclusions, of this class, observed on 1 square millimeter must therefore be multiplied by $\frac{1000}{6.75}=148$ to give the number in the volume.

For class 9, 3.24\% of the inclusions will be observed, and the multiplying factor is reduced to 31 .

\begin{tabular}{|c|c|c|c|c|c|}
\hline Area class & $\begin{array}{l}\text { Diameter } \\
\text { (microns) }\end{array}$ & $\begin{array}{l}\text { Length } \\
\text { (microns) }\end{array}$ & $\begin{array}{l}\text { Particles } \\
\text { in class } \\
\end{array}$ & $\begin{array}{c}\text { Particles per } \\
\text { square millimeter } \\
\end{array}$ & $\begin{array}{l}\text { Particles per } \\
\text { cubic millimeter }\end{array}$ \\
\hline 0 & 2.5 & 6.75 & 7 & 39.63 & 5873 \\
\hline 2 & 3.5 & 9.45 & 6 & 33.96 & 3606 \\
\hline 4 & 5.0 & 13.5 & 3 & 16.98 & 1260 \\
\hline 5 & 6.0 & 16.2 & 2 & 11.34 & 700 \\
\hline 6 & 7.0 & 18.9 & 6 & 33.96 & 1800 \\
\hline 7 & 8.5 & 23.0 & 3 & 16.98 & 741 \\
\hline 9 & 12.0 & 32.4 & 1 & 5.668 & 175 \\
\hline
\end{tabular}

Total estimated particles of 2.5 micron diameter and larger, per cubic millimeter is 14,155 .

Estimated probable error is $20 \%$

A-7 Probability for One Inclusion to Occur in a Random Fifty Micron Diameter Sphere of NBS 461 Steel

The volume of the fifty micron sphere is 65,450 cubic microns; there will be 15,279 such spheres per cubic milimeter. The volume of an inclusion is simply its length times the area of its base. The volume percent of such an inclusion is its volume divided by 65,450 , and its weight percent is approximately $(0.23 / 0.40)$ times the volume percent.

On the average, there will be $14,000 / 15,279$ (0.93) inclusions, or about 1 inclusion per $50 \mu$ sphere which is equivalent to 0.23 percent by weight. For the inclusions to have a 1 percent effect on the results by weight, about 2 percent by weight of the inclusions would be required which corresponds to the presence of about 8 inclusions of average size in the $50 \mu$ sphere. Assuming these inclusions are randomly distributed in the steel, the chance of finding 8 in a $50 \mu$ sphere is negligible.

Area Inclusions per Volume* of Total volume* of Probability for Volume Weight class cubic millimeter one inclusion inclusion per $\mathrm{mm}^{3}$ one inclusion percent percent

$\begin{array}{crrrrrr}0 & 5873 & 35.5 & 208,000 & 0.384 & 0.054 & 0.031 \\ 2 & 3606 & 99.2 & 358,000 & 0.236 & 0.152 & 0.087 \\ 4 & 1260 & 284 & 358,000 & 0.082 & 0.434 & 0.250 \\ 5 & 700 & 477 & 334,000 & 0.046 & 0.729 & 0.419 \\ 6 & 1800 & 795 & 1,431,000 & 0.118 & 1.21 & 0.696 \\ 7 & 741 & 1366 & 1,012,000 & 0.048 & 2.09 & 1.20 \\ 9 & 175 & 3842 & 672,000 & 0.011 & 5.87 & 3.38 \\ \text { Totals } & 14,155 & --- & 4,373,000 & 0.926 & -.-1\end{array}$

\footnotetext{
*Volumes are in cubic microns; hence, 4,373,000 corresponds to 0.44 volume percent in one cubic millimeter ( 109 cubic microns)
} 


\section{Announcement of New Publications on \\ Standard Reference Materials}

Superintendent of Documents

Government Printing Office

Washington, D. C. 20402

Dear Sir:

Please add my name to the announcement list of new publications to be issued in the series: NBS Miscellaneous Publication 260 - Standard Reference Materials.

Name

Company

Address

City State Zip Code

(Notification key N-330) 



\section{Announcement of New Publications on}

Standard Reference Materials

Superintendent of Documents

Government Printing Office

Washington, D. C. 20402

Dear Sir:

Please add my name to the announcement list of new publications to be issued in the series: NBS Miscellaneous Publication 260 - Standard Reference Materials.

Name

Company

Address

City State Zip Code

(Notification key N-330) 
